\section{Crossing the Rubicon}

\author{
(D) M. Castillo, Editor-in-Chief
}

lision you commit a crime, it is well-known that it is better to face the judge in the morning than later in the day. Studies show that criminals are less likely to be convicted if their case is heard in the early morning than in the late afternoon. ${ }^{1}$ Although the above scenario will hopefully never affect any of us neuroradiologists, I do wonder how it affects our daily work. Am I more likely to make the wrong decision at the end of a long day in the reading room? As an editor, am I more likely to accept or reject articles late in the evening?*

Repeated judgments and decisions exhaust one's mental resources, especially those related to executive functions and thus influence the way we make choices leading to intuitive rather than rational decision-making. Lesson: never buy a car late in the afternoon; do it early, during the weekend, and after sleeping well the night before. Individuals who buy their cars when tired are more likely to accept whatever the manufacturers say about their products. ${ }^{2}$ Car salespersons know how to play the game as they go back and forth to their managers, each time forcing you to make new decisions (paint type, type of wheels, leather or standard cloth, and so forth) that wear you down so that when the time to make the final decision to buy the car comes, you are exhausted and just buy it as is. Candy manufacturers are also experts at decision fatigue, and they generally place their (junkier and cheaper) products by the supermarket cashier, so when one is exhausted from shopping, poor decision-making kicks in and one ends up buying all sorts of junk food. Making more decisions during one's day does not make one better at them; on the contrary, it makes for worse choices. The impulsive decision to answer a controversial e-mail when fatigued is nearly always the wrong one; something that I learned the painful way.

The Rubicon decision model states that there are 3 stages to decision-making: first a predecisional (orientation) stage and last a postdecisional stage (also called emergence and reinforcement stages), which are separated by a Rubicon (named after the river in northern Italy that Caesar crossed resulting in a civil war between Gaul and Rome). Thus, the expression "crossing the Rubicon" refers to making an irreversible decision. When one makes the decision to click on the approve button for an imaging report, the "imaging interpretation Rubicon" has been crossed. Crossing the Rubicon is one of the most exhausting stages of decisionmaking, so it should not be surprising that we radiologists feel drained by the end of the day.

The Rubicon process is even more complicated when a clearcut decision cannot be made and one must make trade-offs (called the conflict stage). Compromise and trade-offs in the predecisional stage are also exhausting. If one cannot afford to buy an item, trade-offs lead to exhaustion and not uncommonly one

\footnotetext{
* Don't worry; I do most of my editor work in the early morning.
}

http://dx.doi.org/10.3174/ajnr.A4107 ends up making a decision based only on price rather than other important features such as quality. Marketing strategies also take advantage of this type of fatigue to time the sale of items when you are indecisive. Fatigue can also work in other ways when you are trying to decide. Many choices, conversely, may not make decisions easier but rather lead to no decisions at all.

Some studies have shown that medical-decision errors often occur under the effects of stress and fatigue. In addition, medical teams are unlikely to discuss these errors and to accept the role that decision fatigue played in them. However, airline cockpit crews are prone to report these errors to help improve their performance. ${ }^{3}$ In the 1950s, commercial airline accidents dropped significantly when it became obvious that many errors arose from incorrect decision-making by pilots and crew. Critical personality features that airlines look for in their pilots include the ability to learn from errors, recognize them in others, and contribute to solving them. Today, more than 7 generations of airline crews have been trained with these features in mind, and aviation accidents are at an all-time low.

Work hours may be limited to avoid fatigue and errors in decision-making. We are all familiar with the application of this concept in regard to the maximum hours that trainees in medicine can work ( 80 per week). These hours include hospital day work, call hours, and time spent in academic activities related to training. Additionally, any other activity for which "attendance is strongly encouraged" (such as off-hours journal clubs) needs to be counted within the allowed 80 hours. When a resident travels to present work at a meeting, this travel also counts as active duty time. Why does this requirement apply to trainees and not us, full-fledged radiologists? I spend about 10-12 hours per day at the hospital, plus an additional 2-3 per day working on AJNR, and countless others doing service and volunteer work. Yet, the ultimate responsibility of making a decision in reporting imaging studies falls on me. Are younger individuals more resilient to fatigue than us older ones? Airline rules apply equally to senior and less experienced crew members.

The origin of limiting the hours trainees can work arose from recommendations made by the Institute of Medicine in 2008 with the intention of limiting trainee fatigue and decision-making errors. Younger trainees are thought to be more affected by fatigue; therefore, they are allowed to work fewer hours than senior ones (16 versus 28 continuous hours). ${ }^{4}$ A study published in the New England Journal of Medicine points out how these new rules made a bad situation even worse. Data from a survey completed by more than 6200 residents showed that residents believed that their schedules, education, and quality of life were actually worse and that patient care was suffering after implementation of the new hour policy in 2011. ${ }^{5}$ This finding makes perfect sense because while it relieved fatigue in first-year trainees, the bulk of the work was shifted to more senior residents who actually compose the largest pool. Another study reported that despite the new work hour requirements, the amount of sleep residents got did not improve. ${ }^{6}$ If limiting duty hours was an attempt to improve patient safety, this also failed and intensive care unit stays are more likely than before the reform. ${ }^{7}$ To be fair, I must mention that 
many other studies (too many to quote here) have shown that errors in laparoscopy and electrocardiogram interpretation, unnecessary prolongation of procedures, and lesser quality physical examinations occur more often when chronically sleep-deprived residents have been involved.

Why limiting duty hours for our trainees failed is difficult to understand. Airline pilots are allowed only 8 hours of flight time in a 24-hour period, and all pilots must rest a minimum of 8 hours between assignments. ${ }^{8}$ For flights lasting more than 12 hours, adequate sleeping facilities outside the flight deck must be provided. Airlines also provide their pilots with "fatigue" training. If pilots nap, why not our residents? The Accreditation Council for Graduate Medical Education actually says, "Strategic napping is strongly suggested in the program requirements ... and should not be scheduled but based upon resident fatigue." 9

Although intuition tells us that working overtime leads to fatigue, this is not always the case. In a survey of 4000 other workers, the amount of nonextreme overtime did not correlate with fatigue. ${ }^{10}$ Moreover, overtime workers had favorable characteristics such as high decision latitude, high job variety, high job demands, and, most important, a high job satisfaction. It appears that personal motivation is what leads these workers to work more while maintaining high satisfaction. This, however, may not be the case in Asia where doctors are exposed to extreme overtime (more than 60 additional hours per week) and chronic fatigue is common. $^{10}$

The key to the failure of the new resident work hour requirements to improve fatigue and decision-making errors may lie in our working environments. In an above-cited study, a positive psychosocial environment was critical to ameliorate the effects of fatigue. ${ }^{10}$ This may be why all of these policies work better in the cockpit than in our reading rooms. Cockpits are highly structured, relatively quiet, free of inconsequential interruptions, and respectful places to work, while our reading rooms with their myriad interruptions by telephone, secretaries, clerks, technologists, students, and other physicians have become stressful, nightmarish environments in which it is difficult to complete the assigned tasks and concentrate on making the correct decisions.

Below are some of the most common problems leading to decision-making mistakes and how I think they relate to radiologists:

1) Not taking enough time. A common problem in my reading room in which 1 fellow, 1 resident, and 1 attending interpret upwards of 100 head CTs and MRIs during the workday (spine and ear, nose, and throat studies are interpreted in different reading rooms that have the same problems).

2) Lacking a peaceful environment (see above). Business folks put it in different language: wallowing in chaos.

3) Not considering priorities. In marketing, this is akin to not doing what is best for you, neglecting your values, avoiding the truth, procrastinating, and ignoring what is right.
4) Learning how to say no. I think that learning when to stop interpreting studies and realizing and accepting fatigue are essential to avoid mistakes. Item 3 comes into play here. In the late afternoon, one must prioritize the studies that need to be read and leave others for later. I have learned something else: There is no reason why a case that one does not understand must be immediately interpreted. Now, I place a preliminary report with a note stating that I would like to think about it for a while. This pause allows me to go to my office and do some research, which has always been a good decision, resulting in more intelligent reports. This is what experts call "timing" your decision.

Well, most of this advice is easier said (written) than done. Fatigue will always affect the way we make decisions, and as our existing medical delivery systems come under stress, more work and fatigue will be the rule rather than the exception. Remember that a good and timely decision does not guarantee a good outcome. Decisions must be plastic; they should be able to change and mold when new information becomes available. An irrevocable decision to cross the Rubicon always carries with it the risk of the Ides of March.

\section{REFERENCES}

1. Danziger S, Levav J, Avnaim-Pesso L. Extraneous factors in judicial decisions. Proc Natl Acad Sci U S A 2011;108:6889-92

2. Levav J, Heitmann H, Herrmann A, et al. Order in product customization decisions: evidence from field experiments. $J$ Polit Econ 2010;118:274-99

3. Sexton JB, Thomas EJ, Halmriech RL. Error, stress, and teamwork in medicine and aviation: cross sectional surveys. BMJ 2000;320: 745-49

4. Fodeman JD. The new resident duty hours fail. National Review Online. August 12, 2012. http://www.nationalreview.com/critical-condition/ 313022/new-resident-duty-hours-fail-jason-d-fodeman. Accessed March 19, 2014

5. Drolet BC, Christopher DA, Fischer SA. Resident's response to dutyhour regulations: a follow-up national survey. N Engl J Med 2010; 363:e34

6. Schumacher DJ, Frintner MP, Jain A, et al. The 2011 ACGME standards: impact report by graduating residents on the working and learning environment. Acad Pediatr 2014;14:149-54

7. Block L, Jarlenski $\mathrm{M}, \mathrm{Wu} \mathrm{AW}$, et al. Inpatient safety outcomes following the 2011 residency work-hour reform. J Hosp Med 2014; 9:347-52

8. Federal Aviation Administration. Fact sheet—pilot flight times, rest, and fatigue. January 27, 2010. http://www.faa.gov/news/fact_sheets/ news_story.cfm?newsId=6762. Accessed March 19, 2014

9. Accreditation Council for Graduate Medical Education. Frequently asked questions: ACGME common duty hour requirements. https://www.acgme.org/acgmeweb/Portals/0/PDFs/dh-faqs2011.pdf. Updated June 18, 2014. Accessed September 19, 2014

10. Beckers D, van der Linden D, Smulders $P$, et al. Working overtime hours: relations with fatigue, work motivation, and the quality of work. J Occup Environ Med 2004;46:1282-89 